\title{
DNA HLA-DRB1 ANALYSIS IN CHILDREN OF POSITIVE MOTHERS AND ESTIMATED RISK OF VERTICAL HIV TRANSMISSION
}

\author{
N. A. GREGGIO*, M. CAMERAN*, C. GIAQUINTO*, F. ZACCHELLO*, D. KOROLIUK † AND \\ V. COLIZZI† \\ * Department of Pediatrics, University of Padova, Italy \\ $\dagger$ Department of Biology and Mathematics and Volterra Centre, University of Rome Tor Vergata, Italy
}

\section{SUMMARY}

RFLP HLA-DRB1 analysis was performed on a total of 83 children born from HIV-infected mothers, 35 of whom were shown to be HIV-infected, while 48 reverted from seropositivity to seronegativity, indicating that they were not infected. Moreover, 89 healthy children were used as controls. It has been found that DRB1-14a and DRB1-13a.4 alleles were not present in the HIV-infected children, but were found in the sero-reverted (HIV-uninfected) children (in the proportion of 9.6 per cent and 5.3 per cent, respectively), and in the controls ( 5.6 per cent and 3.9 per cent, respectively). The possible correlation between DR and risk of HIV transmission from mother to baby was analysed considering every single allele, estimated by the ratio between the number of infected children and the number of all children born from seropositive mothers. There was also introduced a statistic $G$ for the control of 'statistical validity' of data.

\section{KEY WORDS HLA-DNA typing Paediatric AIDS Vertical transmission of HIV Risk estimation}

\section{INTRODUCTION}

The genetic susceptibility to HIV infection and subsequent AIDS disease is still a controversial issue (Enlow et al., 1983; Jeannet et al., 1989), and no strict HLA linkage has been found. In fact most studies have associated HLA specificities with HIV-related diseases. Examples include the association between HLA-DR2 or DR5 and Kaposi's sarcoma (Pollak et al., 1983; Smeraldi et al., 1986); the association between HLA-DR5 and CD8 lymphocytosis and sicca syndrome (Iescu et al., 1989); HLA-A1, -B8, -DR3, and rapid decline in T4 cells coupled with the development (in haemophiliacs) of HIV-related symptoms within a short time after being infected (Steel et al., 1988; Mann et al., 1988; Kaslow et al., 1990). Moreover, more recently the frequency of HLA-DR3 was found to be three times higher in HIV-infected children born from infected mothers compared to HIV-uninfected infants born to infected mothers (Kilpatrick et al., 1991). However, a similar analysis conducted in this study with a larger sample population did not identify any significant difference in HLA-DR3 frequency between the two groups.

Tissue typing for HLA-A, -B and -DR antigens gives a general idea of the haplotype. However, considering AIDS pathogenesis and the involvement of $\mathrm{CD}^{+}{ }^{+} \mathrm{T}$

Correspondence to: Dr N. A. Greggio, Department of Pediatrics, University of Padova, Via Giustiniani, 3, 35128 Padova, Italy. 
cells which express and recognize HIV antigens in the context of HLA class II molecules, molecular typing using RFLP of HLA class II gene variations would be more suitable for investigating the association between HLA and HIV infection.

Thus, in an attempt to determine one of the causes of the 'selectivity' encountered in transplacental transmission, molecular typing was carried out on children born from HIV-infected mothers.

\section{SUBJECTS AND METHODS}

Peripheral blood lymphocytes (PBL) from 83 newborns or infants born from HIV-1 infected mothers and 89 healthy children were used for molecular typing by RFLP. The HIV-infected mothers were drug users. During the series of follow-up tests carried out using PCR and viral cultures to identify the presence of HIV-infection, it was found that 35 children were HIV-infected, while the other 48 were HIVuninfected. It needs to be stressed, however, that in our total cohort the vertical transmission rate is about 15 per cent in these infants (Giaquinto et al., 1992). DNA was extracted from each individual's PBL using standard techniques.

The genomic DNA was subjected to restriction enzyme digestion, electrophoresis, and Southern blotting followed by hybridization with specific cDNA coding for the second exon of the HLA-DRBl gene (Bidwell et al., 1988). Polymorphic fragments were assigned as described in the 'RFLP Standardization Reports' of the tenth HLA workshop (Marcadet et al., 1989). Statistical analysis was performed using the software package VLTSTAT (Accardi et al., 1992).

\section{RESULTS AND DISCUSSION}

Table 1 shows the haplotype distribution of $35 \mathrm{HIV}$-infected and $48 \mathrm{HIV}$-uninfected children born from HIV-infected mothers (total 83 children).

Table 2 represents the allele distribution in the 83 children. Table 2 also includes allele distribution in a control population of 89 children (178 alleles) all from the same region. The haplotype distribution is extremely variable because of the very wide number of possible allele combinations. That is why, in order to study possible correlations between DRB1 and the risk of vertical HIV transmission, we analyse the data not for DRB1 in specific combinations, but for every DRB1 allele met in any combination at least once.

As can be seen from Table 2, the allele distribution in HIV-infected children is comparable to that of the controls. No single allele occurs with significantly different frequency in the first group. It is noteworthy that the alleles DRB1-14b and DRB1-10 are very infrequent in all three groups under study, while alleles DRB114a and DRB1-13a.4 are absent in HIV-infected children, but frequent in the others two groups.

To approximate the real risk of transmission of infection, it is possible to introduce the parameter $R$ of risk for every allele as

$$
R=\frac{\text { number of infected children }}{\text { number of all children }}
$$


Tabie 1. HLA-DR haplotype distribution in children born from HIV-infected mothers (number of cases typed)

\begin{tabular}{|c|c|c|c|c|c|}
\hline \multicolumn{3}{|c|}{ Children HIV-infected } & \multicolumn{3}{|c|}{ Children HIV-uninfected } \\
\hline \multicolumn{2}{|c|}{$\begin{array}{l}\text { DRBI allele } \\
\text { combination }\end{array}$} & \multirow{2}{*}{$\begin{array}{c}\begin{array}{c}\text { Number } \\
\text { of cases } \\
(35)\end{array} \\
1\end{array}$} & \multicolumn{2}{|c|}{$\begin{array}{l}\text { DRBI allele } \\
\text { combination }\end{array}$} & \multirow{2}{*}{$\begin{array}{c}\begin{array}{c}\text { Number } \\
\text { of cases } \\
(48)\end{array} \\
4\end{array}$} \\
\hline 1 & 1 & & 1 & 15 & \\
\hline 1 & $13 \mathrm{a} \cdot 1$ & 2 & 1 & 12 & 1 \\
\hline 1 & 4 & 1 & 1 & $17 \cdot 1$ & 1 \\
\hline 1 & $17 \cdot 2$ & 1 & 1 & $17 \cdot 2$ & 1 \\
\hline 1 & 11 & 1 & 11 & 4 & 2 \\
\hline 11 & 11 & 2 & 11 & $13 a \cdot 4$ & 4 \\
\hline 11 & 8 & 1 & 11 & $14 \mathrm{a}$ & 4 \\
\hline 11 & 15 & 1 & 11 & 11 & 3 \\
\hline 11 & 16 & 1 & 11 & 10 & 1 \\
\hline 11 & $13 a \cdot 1$ & 1 & 11 & 16 & 2 \\
\hline 11 & $7 \cdot 1$ & 1 & 11 & $7 \cdot 2$ & 2 \\
\hline 11 & $7 \cdot 2$ & 1 & 11 & $7 \cdot 1$ & 1 \\
\hline 11 & $17 \cdot 2$ & 1 & 11 & $17 \cdot 1$ & 2 \\
\hline 11 & $17 \cdot 1$ & 1 & 11 & 8 & 1 \\
\hline $17 \cdot 2$ & $7 \cdot 2$ & 1 & $7 \cdot 2$ & $7 \cdot 2$ & 1 \\
\hline $17 \cdot 2$ & 15 & 1 & $7 \cdot 2$ & $17 \cdot 1$ & 2 \\
\hline $17 \cdot 2$ & $17 \cdot 2$ & 1 & $7 \cdot 2$ & 15 & 1 \\
\hline $17 \cdot 2$ & $7 \cdot 1$ & 1 & 4 & $13 \mathrm{a} \cdot 4$ & 1 \\
\hline $7 \cdot 1$ & $13 a \cdot 1$ & 1 & 4 & $14 \mathrm{a}$ & 1 \\
\hline $7 \cdot 1$ & $13 b$ & 1 & 15 & $17 \cdot 2$ & 1 \\
\hline $7 \cdot 1$ & 4 & 1 & 15 & 16 & 2 \\
\hline $7 \cdot 2$ & $13 \mathrm{a} \cdot 1$ & 1 & 15 & $14 a$ & 1 \\
\hline $7 \cdot 2$ & 15 & 1 & 12 & $14 a$ & 1 \\
\hline $7 \cdot 2$ & 12 & 1 & 12 & $13 a \cdot 1$ & 1 \\
\hline $7 \cdot 2$ & 8 & 1 & $17 \cdot 2$ & $17 \cdot 2$ & 1 \\
\hline 15 & 15 & 1 & $17 \cdot 2$ & $14 \mathrm{a}$ & 1 \\
\hline 15 & $17 \cdot 1$ & 1 & $17 \cdot 2$ & 8 & 1 \\
\hline 15 & 4 & 2 & $13 a \cdot 3$ & 16 & 1 \\
\hline 15 & 16 & 1 & $13 a \cdot 3$ & $17 \cdot 1$ & 1 \\
\hline 4 & $13 \mathrm{a} \cdot 3$ & 1 & $17 \cdot 1$ & $14 \mathrm{a}$ & 1 \\
\hline 4 & $17 \cdot 1$ & 1 & $7 \cdot 1$ & $17 \cdot 1$ & 1 \\
\hline 8 & $13 \mathrm{a} \cdot 1$ & 1 & & & \\
\hline
\end{tabular}

Applying the software package VLTSTAT, we compute the risk $R$ and its grade of confidence $G$ (Table 3) defined below.

In order to measure how accurately the parameter $R$ estimates the real risk, let us determine a 'confidence interval' for the parameter $R$ in the usual way: fixing a number $\alpha: 0 \leqslant \alpha \leqslant 1$ which will denote some probability termed the 'confidence level', we find the interval $[B, T]$ as follows: the parameter $R$ belongs to the interval $[B, T]$ with the given probability $\alpha$, that is:

$$
\text { Prob. }\{B \leqslant R \leqslant t\}=\alpha
$$

For calculation of the parameters $R, B, T$ we shall apply the rules of binomial distribution for random samples and fix the confidence level $\alpha$ to be $0 \cdot 8$ ( 80 per cent). 
Table 2. HLA class II allele distribution in children born from HIV-infected mothers and controls (number of chromosomes examined)

\begin{tabular}{cccc}
\hline $\begin{array}{l}\text { DRBI } \\
\text { allele }\end{array}$ & $\begin{array}{c}\text { HIV-infected } \\
(70)\end{array}$ & $\begin{array}{c}\text { HIV-uninfected } \\
(96)\end{array}$ & $\begin{array}{c}\text { Controls } \\
(178)\end{array}$ \\
\hline 1 & 7 & 7 & 19 \\
15 & 9 & 9 & 16 \\
16 & 2 & 5 & 15 \\
$17 \cdot 1$ & 3 & 8 & 8 \\
$17 \cdot 2$ & 7 & 6 & 7 \\
4 & 6 & 4 & 8 \\
11 & 13 & 25 & 42 \\
12 & 1 & 3 & 7 \\
$13 \mathrm{a} \cdot 3$ & 1 & 2 & 6 \\
$13 \mathrm{a} \cdot 1$ & 6 & 1 & 5 \\
$14 \mathrm{~b}$ & 0 & 0 & 3 \\
$13 \mathrm{a} \cdot 4$ & 0 & 5 & 7 \\
$14 \mathrm{a}$ & 0 & 9 & 10 \\
$13 \mathrm{~b}$ & 1 & 0 & 2 \\
$7 \cdot 1$ & 5 & 2 & 7 \\
$7 \cdot 2$ & 6 & 7 & 9 \\
8 & 3 & 2 & 4 \\
10 & 0 & 1 & 3 \\
\hline
\end{tabular}

Table 3. Values of the parameters $R$ and $G$ and of some accompanying characteristics

\begin{tabular}{lccccc}
\hline $\begin{array}{l}\text { DRBI } \\
\text { allele }\end{array}$ & $\begin{array}{c}\text { Number of } \\
\text { cases }\end{array}$ & $\begin{array}{c}\text { Statistical } \\
\text { equivalence }\end{array}$ & $\begin{array}{c}\text { Statistics } \\
\text { HIV }+/ \text { HIV }-\end{array}$ & Risk, $R$ & $\begin{array}{c}\text { Grade of } \\
\text { confidence, } G\end{array}$ \\
\hline 11 & 38 & - & $13 / 25$ & $0 \cdot 34$ & $0 \cdot 78$ \\
$14 \mathrm{a}$ & 9 & 38 & $0 / 9$ & 0 & $0 \cdot 77$ \\
15 & 18 & - & $9 / 9$ & $0 \cdot 50$ & $0 \cdot 66$ \\
$13 \mathrm{a} \cdot 4$ & 5 & 16 & $0 / 5$ & 0 & $0 \cdot 63$ \\
1 & 14 & - & $7 / 7$ & $0 \cdot 50$ & $0 \cdot 60$ \\
$17 \cdot 1$ & 11 & 13 & $3 / 8$ & $0 \cdot 27$ & $0 \cdot 59$ \\
$17 \cdot 2$ & 13 & - & $7 / 6$ & $0 \cdot 54$ & $0 \cdot 59$ \\
$7 \cdot 2$ & 13 & - & $6 / 7$ & $0 \cdot 46$ & $0 \cdot 59$ \\
$13 \mathrm{a} \cdot 1$ & 7 & 11 & $6 / 1$ & $0 \cdot 86$ & $0 \cdot 56$ \\
4 & 10 & - & $6 / 4$ & $0 \cdot 60$ & $0 \cdot 54$ \\
16 & 7 & - & $2 / 5$ & $0 \cdot 29$ & $0 \cdot 48$ \\
$7 \cdot 1$ & 7 & - & $5 / 2$ & $0 \cdot 71$ & $0 \cdot 48$ \\
8 & 5 & - & $3 / 2$ & $0 \cdot 60$ & $0 \cdot 36$ \\
12 & 4 & - & $1 / 3$ & $0 \cdot 25$ & $0 \cdot 35$ \\
$13 \mathrm{a} \cdot 3$ & 3 & - & $1 / 2$ & $0 \cdot 33$ & $0 \cdot 23$ \\
\hline
\end{tabular}


Now our problem is to calculate the grade of confidence for our estimations. For given confidence level $\alpha$ :

$$
L=T-B(\text { top }- \text { bottom })
$$

the length of confidence level. As the estimate of the grade of confidence of our estimations we take the value

$$
G=1-L
$$

This parameter takes its values in the interval $[0,1]$ and is equal to 1 when the confidence level has the length 0 , i. e. the estimate is precise and vice versa, $G=0$ if the estimate is dispersed in the whole interval $[0,1]$. The computation of $G$ presented in Table 3 has been done for the level of confidence $\alpha=0.8$ ( 80 per cent). But in fact, we have verified that one can choose any value $\alpha \varepsilon[0.7,0.98]$ without any change of qualitative picture.

Estimation of the grade of confidence for the risk parameter $R$ by the length of confidence interval (statistic $G$ ) is the most appropriate in this case. Other statistical treatments are less adequate; for example, dispersion: if calculated for alleles 13a.4 and 14a, both the risks $R$ and the dispersions $D$ are equal to 0 , but the statistics $G$ in this case differ from 0 and have values corresponding to the size of random samples.

The results of evaluation of risks $R$ and their grades of confidence are given in the Table 3. The meaning of the column 'Statistical equivalence' is explained below. For convenience, the lines of Table 3 are ordered by values of the parameter $G$. Hence, the confidence of results is highest for the first line and worst for the last line. The values reported in the column 'Number of cases', are not in strictly decreasing order, indicating that increasing the number of observations does not always increase confidence. For example, the confidence of risk estimation for DRB1-11 and DRB1$14 \mathrm{a}$ are almost the same, despite very different volumes of samples ( 38 data against 9 data). It can be explained by the fact that in the second case we have 'homogeneity of outcomes': all 9 babies have seroreverted. The probability of such 'coincidence' is:

$$
\text { Prob. }(0 \text { infected and } N \text { seroconverted })=\beta^{N}
$$

where $\beta$ is the probability of being seroreverted for a baby with allele $14 \mathrm{a}$; so when $\beta$ differs markedly from 1 , this probability decreases to 0 very rapidly. This fact confirms again the adequacy of the statistic $G$. Therefore, in the cases of 'homogeneous outcomes', the confidence of risk essentially increases and, as we have mentioned, only 9 data in the 13 th case are 'statistically equivalent' to 38 data in the 7th case of 'mixed outcomes'.

Let us consider the first four lines of Table 3, as the most confident results (statistical validity at least 16 observations). We find that for DRB1-14a and for DRB1-13.4 the risk of transmission is minimal while for DRB1-11 and for DRB1-15 it is not so (the empirical probabilities of transmission are correspondingly $1 / 3$ and $1 / 2$ ).

Moreover, considering the results where the confidence $G$, is much lower, for example, alleles DRB1-7.1 and DRB1-7.2, we have rather different risk values $(0 \cdot 71$ and $0 \cdot 46)$. We have tested the hypothesis that these risks are in fact the same with variation in levels of significance. The result is that they do not coincide for any level.

Although several studies have been performed to associate HLA type with HIV susceptibility and progression of the disease in adults (Steel et al., 1988; Pollack 
et al., 1983; Mann et al., 1988), only one study has been published so far on the HLA frequencies of children born of HIV-infected mothers (Kilpatrick et al., 1991). In that study, 8 children out of 53 at risk were infected, and the allele distribution showed that DR3 was three times more common in infected children compared to uninfected. A high frequency of DR3 was also found in HIV-infected adults (Steel et al., 1988).

The study reported in this paper analyses 83 children born of infected mothers and of these 35 were HIV-infected. The HLA specificities were determinated by RFLP technique. The value of such technique for analysis of HLA system lies in its ability to demonstrate allelic variations within specificities that do not show variation at the serological level (Peter et al., 1992). The importance of using DNA analysis is exemplified by the above reported association between DR3 and HIV susceptibility (Steel et al., 1988). DR3 is split at the DNA level into $17 \cdot 1$ and $17 \cdot 2$, which are respectively associated, as mentioned above, with different risk of levels, as determined by the parameter $R$. The conclusion is that the association between DR3 and HIV infection may be tested more rigorously by considering the 17.2 split. Moreover, with RFLP analysis it is possible to identify a strong association of the $14 \mathrm{a}$ and 13a.4 alleles which are splits of DR6, with protection against infection (high grade of confidence).

Sequencing of the second exon of the DR region of the B1 chain of those HIVuninfected children and controls who are carriers of alleles DRB1-14a and DRB1$13 \mathrm{a} .4$ is in progress Identification of specific sequences associated with these peptides would substantiate the possibility that given sequences play an important role in the MHC-mediated immune response and hence in protection against HIV.

\section{ACKNOWLEDGEMENTS}

This work was supported by I.S.S. IV Progetto AIDS and by C.N.R. (P.F.FAT.MA and GNAFA).

\section{REFERENCES}

Accardi, L., Koroliuk, D. (1992). Statistical package VLTSTAT: a New Approach to Robustness. Volterra: Preprint p. 112.

Bidwell, J.L., Bidwell, E.A., Savage, D.A., Middleton, D., Dlouda, P.T., Bradley, B.A. (1988). A DNA-RFLP typing system that positively identifies serologically well-defined and ill-defined HLA-DR and DQ alleles, including DRw 10. Transplantation, 45, 640-646.

Enlow, R.W., Nunez-Rodan, A., LoGalbo, P., Mildvan, D., Mathur, U., Winchester, R.J. (1983). Increased frequency of HLA-DR5 in lymphadenopathy stage of AIDS. Lancet, 2 , $51-52$.

Giaquinto, C., Giacomet, V., Pagliaro, A., Ruga, E., Cozzani, S., D’Elia, R., Newell, M.L. (1992). Social care of children born from HIV-infected parents. Lancet, 339, 189-190.

Itescu, S., Brancato, L.J., Winchester, R. (1989). A Sicca syndrome in HIV infection; association with HLA-DR5 and CD8 lymphocytosis. Lancet, 466-468.

Jeannet, M., Sztajzel, R., Carpentier, N., Hirschel, B., Tiercy, J.-M. (1989). HLA antigens are risk factors for development of AIDS. J. AIDS, 2, 28-32.

Kaslow, R.A., Duquesnoy, R., Vanraden, M., Dingsley, L., Marrari, M., Friedman, H., Su, S., Saah, A.Y., Detels, R., Phair, J., Rinaldo, C. (1990). A1, Cw7, B8, DR3 HLA antigen combination associated with rapid decline of T-helper lymphocytes in HIV-1 infection. Lancet, 335, 927-930. 
Kilpatrick, D.C., Hague, R.A., Yapand, P.L., Mok, J.Y.Q. (1991). HLA antigen frequencies in children born from HIV-infected mothers. Dis. Markers, 9, 21-26.

Mann, D.L., Murray, C., Yarchoan, R., Blattner, W.A., Goedert, J.J. (1988). HLA antigen frequencies in HIV-1 seropositive disease free individuals and patients with AIDS. $J$. AIDS, 1, 13-17.

Peter, J.B., Hawkins, B.R., Path, M.R.C. (1992). The new HLA. Arch. Pathol. Lab. Med., 116, 11-15.

Pollack, M.S., Safai, B., Dupont, B. (1983). HLA-DR5 and DR2 are susceptibility factors for acquired immunodeficiecy syndrome with Kaposi's sarcoma in different ethnic subpopulation. Dis. Markers, 1, 135-139.

Scorza Smerladi, R., Fabio, G., Lazzarin, A., Eisera, N.B., Moroni, M., Zanussi, C. (1986). HLA-associated susceptibility to acquired immunodeficiency syndrome in Italian patients with human-immunodefiency virus infection. Lancet, 2, 1187-1189.

Steel, C.M., Beatson, D., Cuthbert, R.J.G., Morrison, H., Ludlam, C.A., Peutherer, J.F., Simmonds, P., Jones, M. (1988). HLA haplotype A1 B8 DR3 as a risk factor for HIV-related disease. Lancet, 28, 1185-1188. 


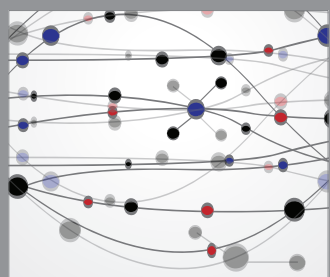

The Scientific World Journal
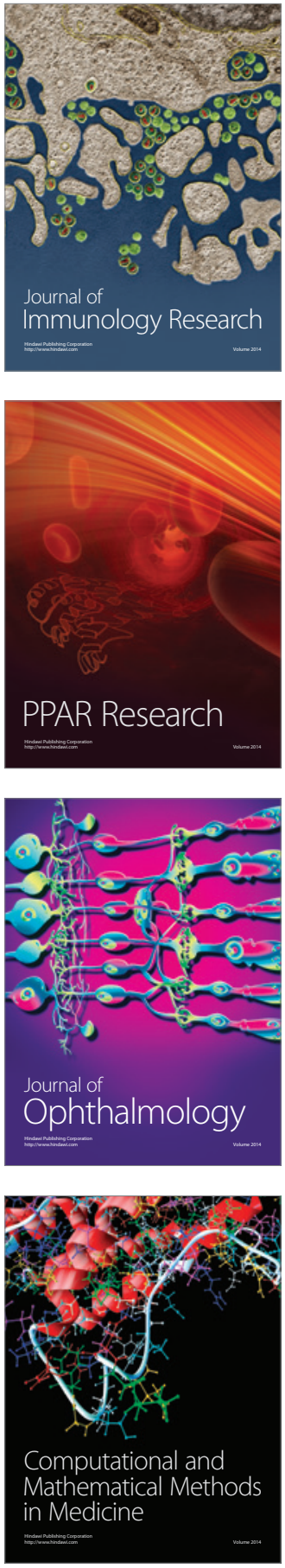

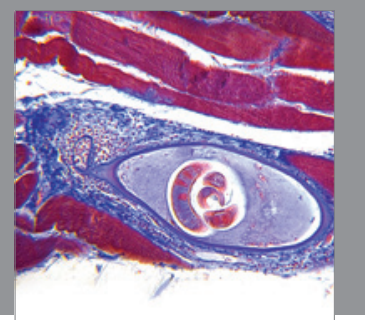

Gastroenterology

Research and Practice
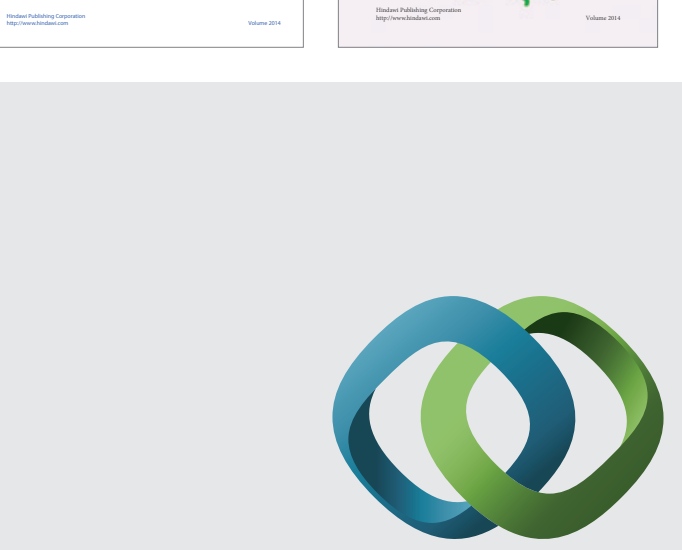

\section{Hindawi}

Submit your manuscripts at

http://www.hindawi.com
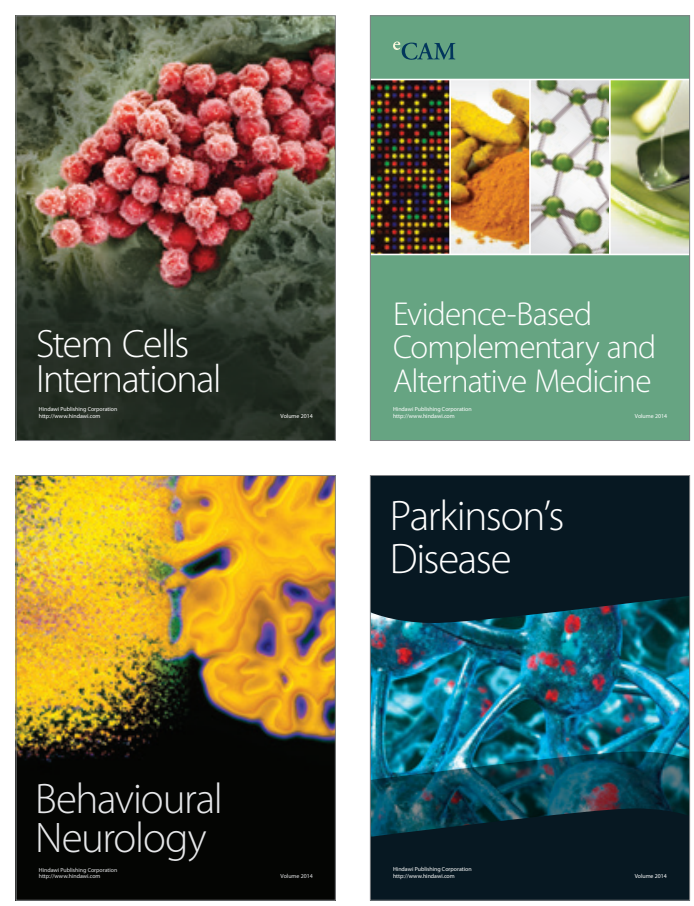

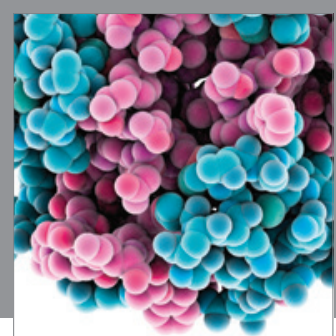

Journal of
Diabetes Research

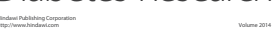

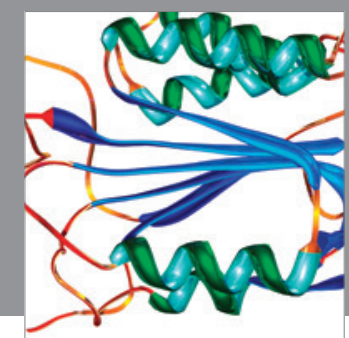

Disease Markers
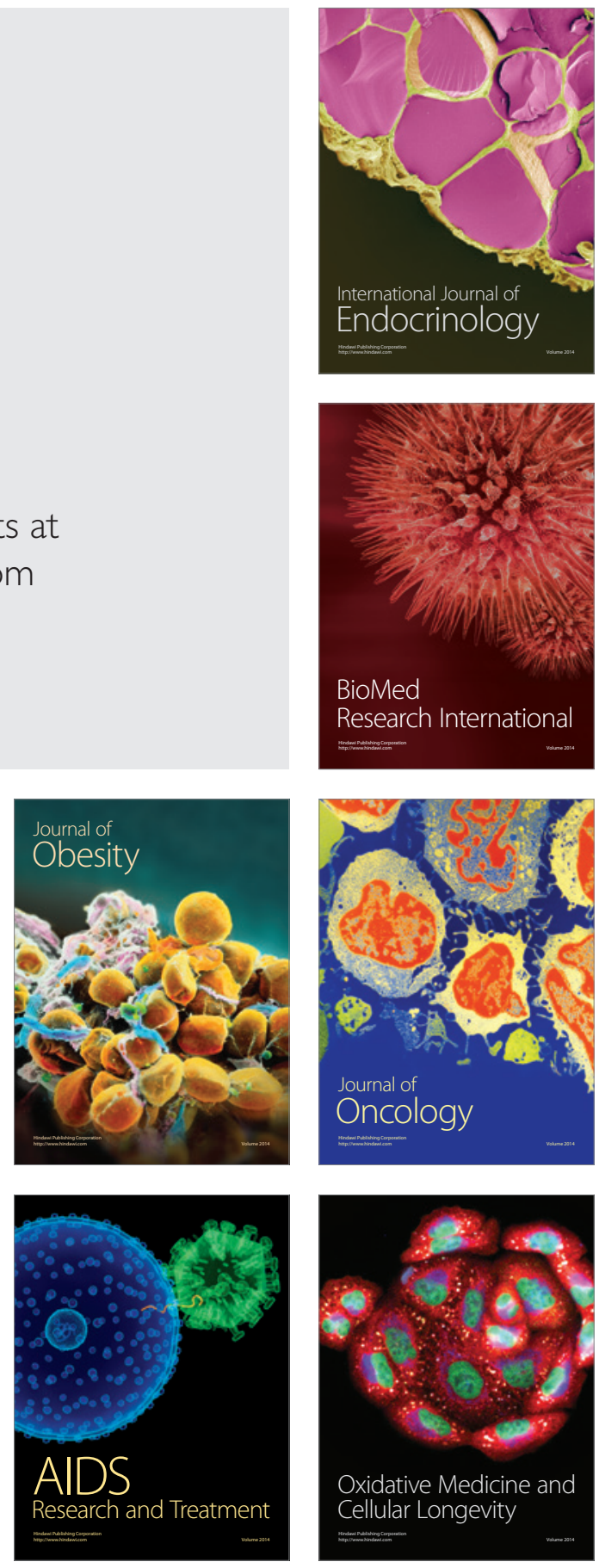